\title{
Os Modelos Médico e Social de DeficiênCIA A PARTIR DOS SIGNIFICADOS DE SEGREGAÇÃO E INCLUSÃO NOS DISCURSOS DE MICHEL FOUCAULT E DE MARTHA NUSSBAUM
}

\begin{abstract}
ANA PAULA BARBOSA-FOHRMANN ${ }^{\dagger}$
RESUMO: Neste artigo, serão abordados preliminarmente os significados de segregação (ou exclusão), integração e inclusão, a partir da interpretação de prescrições de documentos-chave internacionais. Num segundo momento, pretendemos extrapolar o âmbito de análise dogmático-jurídica e examinaremos os discursos de deficiência de Michel Foucault e de Martha Nussbaum. Michel Foucault, através da crítica histórica, lança seu olhar sobre o modelo médico de segregação ou exclusão, enquanto Martha Nussbaum, ao criticar a teoria moral de Kant e a de justiça procedimental de Rawls, propõe um modelo social mais inclusivo para as pessoas com deficiência. $O$ modelo médico de integração não será discursivamente abordado aqui.
\end{abstract}

PAlavRAS-CHAVE: Discursos sobre Deficiência; Segregação; Inclusão; Modelo Médico; Modelo Social.

\footnotetext{
$\uparrow$ Professora Adjunta de Teoria do Direito da Faculdade Nacional de Direito e Professora Permanente do Programa de Pós-Graduação em Direito da Universidade Federal do Rio de Janeiro. E-mail: anapbarbosa@direito.ufrj.br.
} 
ABSTRACT: First, this paper will approach the meanings of segregation (or exclusion), integration and inclusion grounded on the interpretation of several provisions of key international documents. Secondly, it intends to overcome the legal analysis and examine Michel Foucault's and Martha Nussbaum's discourses on disabilities. Michel Foucault, by means of a historical criticism, focuses his analysis on the medical model of segregation (or exclusion) while Martha Nussbaum proposes a social model that intends to be more inclusive of persons with disabilities. The medical model of integration will not be tackled in this paper.

KEYWORDS: Discourses on Disabilities; Segregation; Inclusion; Medical Model; Social Model.

\section{SUMÁRIO:}

I. Conceitos Preliminares:

SEGREGAÇão, INTEGRAÇão E INCLUSÃO..........................................738

II. MICHEL FOUCAULT ................................................................................744

III. MaRTha NuSSBAUM...............................................................................748

IV. CONCLUSÃO ......................................................................................752

V. REFERÊNCIAS................................................................................752

\section{TABLE OF CONTENTS:}

I. PRELIMINARY CONCEPTS:

SEGREGATION, INTEGRATION AND INCLUSION.................................738

II. MICHEL FOUCAULT ................................................................................744

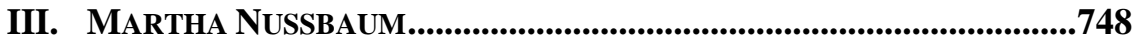

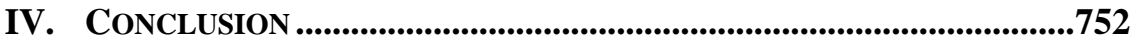

V. REFERENCES ..........................................................................................752 


\section{CONCEITOS Preliminares: SegregaÇão, INTEGRaÇÃo E INCLUSÃO ${ }^{1}$}

Antes de adentrar em Foucault, é importante que compreendamos o significado de segregação (ou exclusão), integração e inclusão nos estudos sobre deficiência. Aqui entendemos os dois primeiros vinculados ao modelo médico, e o último ao modelo social. Quando analisamos no modelo médico, pensamos que a Medicina considera a deficiência uma doença a ser curada ou uma doença simplesmente incurável. Pensamos ainda, de um lado, em "exclusão sinônima de segregação" e, de outro lado, em "integração" das pessoas com deficiência, obedecendo a lógica do modelo médico. Excluir significa apartar a pessoa de qualquer convívio social, enquanto que integrar significa que a pessoa com deficiência empreende esforços próprios para se adaptar ao meio social, em que se encontra, composto por pessoas "normais", ou a um meio especializado, que permite que a pessoa com deficiência sensorial, mental ou intelectual conviva e interaja apenas com seus pares. Tanto no primeiro caso de "exclusão" quanto no segundo de "integração" a lógica é a deficiência considerada como uma doença e, portanto, sujeita a exame e tratamento médico. Já o modelo social, vinculado à lógica da inclusão, coloca o acento no meio social e não na pessoa que deve ser excluída dele ou que necessariamente tem de empreender esforços para a ele se adaptar. É o meio que tem, ao contrário, de se adaptar à pessoa e, para isso, necessita eliminar as barreiras de acessibilidade e repensar o sentido de adaptação.

A prevalência do modelo social de inclusão sobre o modelo médico de integração passou a fazer parte de princípios e políticas internacionais especialmente a partir do "Ano Internacional das Pessoas Deficientes", em 1981, e do Programa de Ação Mundial de Ação sobre as Pessoas Portadoras de Deficiência, lançado em $1982 .^{2}$ A partir de então, foi fixada

${ }^{1}$ Cp. com a seção "IV. Do Modelo Social a partir da Convenção sobre Direitos das Pessoas com Deficiência de 2006". BARBOSA-FOHRMANN, Ana Paula; KIEFER, Sandra Filomena Wagner. Modelo Social de Abordagem dos direitos humanos das pessoas com deficiência. In: Joyceane Bezerra Menezes (Org.). Direito das pessoas com deficiência psíquica e intelectual nas relações privadas: Convenção sobre os direitos da pessoa com deficiência e Lei Brasileira de Inclusão. Rio de Janeiro, RJ: Editora Processo, 2016, p. 76-80.

2 "Programa de Ação Mundial para as Pessoas com Deficiência", 1982. A Resolução ONU n 37/52, de 3 de dezembro de 1982, estabelece diretrizes para Ações Nacionais (participação de pessoas com deficiência na tomada de decisões, prevenção, 
a Década das Pessoas com Deficiência das Nações Unidas, ${ }^{3}$ como parte da estratégia para que, dentre outros, os países pudessem implementar o aludido Programa de Ação Mundial. ${ }^{4}$ Os princípios e conceitos do modelo social de deficiência começaram efetivamente a predominar nas políticas e legislação voltadas às pessoas com deficiência.

A positivação do modelo social de inclusão, em sua plenitude, viria apenas em 2006, com a Convenção Internacional sobre os Direitos das Pessoas com Deficiência (CDPD). ${ }^{5}$ A Convenção é o primeiro tratado internacional do século XXI e também é o primeiro que versa especificamente sobre as pessoas com deficiência no âmbito do sistema de proteção de direitos humanos da $\mathrm{ONU}$, marcando a mudança de paradigma na trajetória do seu tratamento jurídico, agora focado no exercício dos direitos humanos. Ela fixa os direitos humanos e as liberdades fundamentais básicas e universais, ${ }^{6}$ como o direito de ir e vir,

reabilitação, ação comunitária e educação do público), Internacionais, Pesquisa e Controle a Avaliação do Programa de Ação Mundial para Pessoas Deficientes.

Disponível em: $<$ http://www.mpdft.mp.br/deficiencia/index.php/legislacao/1-direitosbasicos-competencia-politica-geral-e-assistencia-social/17-apendice-n-1/13uniao/uniao-resolucoes/714-resolucao-da-onu-n-3752-de-03-de-dezembro-de-1982>.

Acesso em: 03 de março de 2016.

${ }^{3}$ A Resolução ONU nº 45/91, de 14 de dezembro de 1990 propõe a execução do Programa de Ação Mundial para as Pessoas com Deficiência e da Década das Pessoas com Deficiência das Nações Unidas. (Implementation of the World Programme of Action concerning Disabled Persons and the United Nations Decade of Disabled Persons). Disponivel em: < http://www.un.org/documents/ga/res/45/a45r091.htm>. Acesso em: 03 de março de 2016.

${ }^{4}$ DEL ÁGUILA, Luis Miguel. La Autonomía de las Personas con Discapacidad como Principio Rector. In: Elizabeth Salmón y Renato Bregaglio (Coords.). Nueve Conceptos Claves para Entender la Convención sobre los Derechos de las Personas con Discapacidad. Lima: Pontificia Universidad Católica del Perú, Instituto de Democracia y Derechos Humanos (IDDHPUCP), 2015, p. 54-55.

${ }^{5}$ Decreto $n^{\circ}$ 6.949, de 25 de agosto de 2009: Promulga a Convenção Internacional sobre os Direitos das Pessoas com Deficiência (CDPD) e seu Protocolo Facultativo.

Disponível em: <http://www.planalto.gov.br/ccivil 03/ ato2007-

2010/2009/decreto/d6949.htm>. Acesso em: 23 de fevereiro de 2016.

${ }^{6}$ Prevê direitos civis, políticos, econômicos, sociais e culturais. Cf. SALMÓN, Elizabeth. El Comité de los Derechos de las Personas con Discapacidad o la Institucionalidad del Derecho Internacional de los Derechos Humanos al Servicio de las Personas con Discapacidad. In: Elizabeth Salmón y Renato Bregaglio (Coords.). Nueve Conceptos Claves para Entender la Convención sobre los Derechos de las 
o direito à acessibilidade, à educação, ao lazer, à cultura, à saúde, à moradia, dentre outros, contemplando instrumentos jurídicos que dão eficácia a eles. Na verdade, não houve criação de novos direitos, mas sua especificação, para que as pessoas com deficiência pudessem deles gozar em igualdade de condições com as demais. Já em seu preâmbulo, a CDPD reconhece expressamente que, apesar dos instrumentos e compromissos existentes até então, as pessoas com deficiência ainda se deparavam com problemas relativos à participação na sociedade e à violação de seus direitos. Assim, a Convenção reforça a visão de proteção e garantia da eficácia desses direitos, com superação da segregação ou exclusão, reconhecendo, pois, a qualidade de sujeito de direito das pessoas com deficiência. ${ }^{7}$ Em suma: protege e promove os direitos que fazem parte do sistema geral dos direitos humanos, mas que têm sido desrespeitados sistematicamente quando se trata de pessoas com deficiência. ${ }^{8}$

Personas con Discapacidad. Lima: Pontificia Universidad Católica del Perú, Instituto de Democracia y Derechos Humanos (IDDHPUCP), 2015, p. 202.

7 FERREIRA, Vandir da Silva; OLIVEIRA, Lilia Novais de. Convenção sobre os Direitos das Pessoas com Deficiência. Associação Nacional dos Membros do Ministério Público de Defesa dos Direitos dos Idosos e Pessoas com Deficiência (AMPID), 2007. Disponível em:

$<$ http://www.ampid.org.br/ampid/Artigos/Convencao Vandir Lilia.php $>$. Acesso em: 23 de outubro de 2015; FONSECA, Ricardo Tadeu Marques da. A ONU e seu Conceito Revolucionário de Pessoa com Deficiência. Associação Nacional dos Membros do Ministério Público de Defesa dos Direitos dos Idosos e Pessoas com Deficiência (AMPID), 2008. Disponível em:

<http://www.ampid.org.br/ampid/Artigos/Onu Ricardo Fonseca.php>. Acesso em: 19 de outubro de 2015; e MARTÍNEZ, María Olga Sánchez; CAYÓN, José Ignacio Solar.

La Convención Internacional sobre los Derechos de las Personas con Discapacidad y su Impacto en la Legislación Autonómica de Cantabria: propuestas de reforma legislativa. Madrid: Dykinson, 2015, p. 25.

8 DEL ÁGUILA, Luis Miguel. La Autonomía de las Personas con Discapacidad como Principio Rector. In: Elizabeth Salmón y Renato Bregaglio (Coords.). Nueve Conceptos Claves para Entender la Convención sobre los Derechos de las Personas con Discapacidad. Lima: Pontificia Universidad Católica del Perú, Instituto de Democracia y Derechos Humanos (IDDHPUCP), 2015, p. 69; e SALMÓN, Elizabeth. El Comité de los Derechos de las Personas con Discapacidad o la Institucionalidad del Derecho Internacional de los Derechos Humanos al Servicio de las Personas con Discapacidad. In: Elizabeth Salmón y Renato Bregaglio (Coords.). Nueve Conceptos Claves para Entender la Convención sobre los Derechos de las Personas con Discapacidad. Lima: 
Ademais, o tratado em tela não é apenas uma estipulação de nãodiscriminação para o exercício de direitos, mas a garantia do seu exercício. De fato, a Convenção acabou por concluir um processo de mudança de paradigma no âmbito internacional, que havia se iniciado nos anos de 1980, pelo qual a deficiência passou a ser uma questão social e de direitos humanos e, portanto, as políticas e todas as respostas ligadas à questão deveriam ter como ponto de partida os direitos humanos, e não mais o assistencialismo, o paternalismo e o integracionismo advindo do modelo médico. Sua motivação político-jurídica está fundada nos princípios da universalidade, indivisibilidade e interdependência dos direitos humanos, conforme seu preâmbulo . E mais, ainda no aludido preâmbulo:

y) Convencidos de que uma convenção internacional geral e integral para promover e proteger os direitos e a dignidade das pessoas com deficiência prestará significativa contribuição para corrigir as profundas desvantagens sociais das pessoas com deficiência e para promover sua participação na vida econômica, social e cultural, em igualdade de oportunidades, tanto nos países em desenvolvimento como nos desenvolvidos. ${ }^{10}$

A CDPD retrata o modelo social, predominante nos dias de hoje (ao menos em teoria e de acordo com as disposições legais), baseado em

Pontificia Universidad Católica del Perú, Instituto de Democracia y Derechos Humanos (IDDHPUCP), 2015, p. 202.

9 FONSECA, Ricardo Tadeu Marques da. A ONU e seu Conceito Revolucionário de Pessoa com Deficiência. Associação Nacional dos Membros do Ministério Público de Defesa dos Direitos dos Idosos e Pessoas com Deficiência (AMPID), 2008.

Disponível em:

<http://www.ampid.org.br/ampid/Artigos/Onu Ricardo Fonseca.php>. Acesso em: 19 de outubro de 2015; e PALACIOS, Agustina; BARIFFI, Francisco. La discapacidad como una cuestión de derechos humanos: una aproximación a la Convención Internacional sobre los Derechos de las Personas con Discapacidad. Madrid: Cinca, 2007 , p. $11 / 49 / 56$.

${ }^{10}$ Decreto nº 6.949, de 25 de agosto de 2009: Promulga a Convenção Internacional sobre os Direitos das Pessoas com Deficiência (CDPD) e seu Protocolo Facultativo.

Disponível em: $<$ http://www.planalto.gov.br/ccivil 03/ ato2007-

2010/2009/decreto/d6949.htm>. Acesso em: 23 de fevereiro de 2016. 
direitos, ${ }^{11}$ também conhecido como "modelo moderno-institucional", ${ }^{12}$ "modelo de direitos humanos da deficiência"13 ou "modelo de barreiras sociais". Nele, o foco não se encontra na pessoa, mas na inabilidade e na falta de preparo da sociedade para se adaptar a ela, reconhecendo-a como sujeito de direitos. Na verdade, entende-se que resulta da sua relação com as barreiras sociais e das relações de poder. ${ }^{14}$

Note-se que a própria Convenção pressupõe o respeito pela dignidade de todos os seres humanos; o respeito à diversidade e à independência das pessoas; o reconhecimento de que a deficiência faz parte da diversidade humana; a não discriminação, a igualdade de oportunidades, além da participação e inclusão na sociedade..$^{15}$ A questão desses direitos está fundada em fatores sociais e não individuais: "los derechos de las personas con discapacidad son, en términos generales, los mismos derechos que posee cualquier persona y, por tanto, su justificación no obedece a rasgos individualizadores o de identidad de un colectivo."16

A inclusão surge como uma conquista no âmbito dos direitos

${ }^{11}$ ASÍS, Rafael de. et al. (Coords.). Sobre la Accesibilidad Universal en el Derecho. Cuadernos "Bartolomé de las Casas", No. 42. Madrid: Dykinson, 2007, p. 13.

12 ESTEBAN, Amparo Cano, et. al. (Coords.) Discapacidad y Políticas Públicas: la experiencia real de la juventud con discapacidad en España. Madrid: Catarata, 2015, p. 14.

${ }^{13} \mathrm{O}$ modelo social possui os mesmos valores básicos que sustentam os direitos humanos, como a dignidade, a liberdade-autonomia, a igualdade de todos os seres humanos. Cf. PALACIOS, Agustina; BARIFFI, Francisco. La discapacidad como una cuestión de derechos humanos: una aproximación a la Convención Internacional sobre los Derechos de las Personas con Discapacidad. Madrid: Cinca, 2007, p. 23. ${ }^{14}$ Para Asís, et. al., é conveniente a adoção de um conceito de deficiência amplo: “De esta manera, podríamos entender que una deficiencia en una función corporal (por ejemplo, un mal funcionamiento del sistema visual), o una construcción del entorno social (falta del sistema de audiodescripción) puede producir una discapacidad, esto es, una situación en la que se dificulta o impide realizar alguna actividad de la vida social (como puede ser, por ejemplo, ver películas de cine)." ASÍS, Rafael de. et al. (Coords.). Sobre la Accesibilidad Universal en el Derecho. Cuadernos "Bartolomé de las Casas", No. 42. Madrid: Dykinson, 2007, p. 50-52.

${ }^{15}$ RODRÍGUEZ, José Antonio Cagigas. Prefacio. In: MARTÍNEZ, María Olga Sánchez; CAYÓN, José Ignacio Solar. La Convención Internacional sobre los Derechos de las Personas con Discapacidad y su Impacto en la Legislación Autonómica de Cantabria: propuestas de reforma legislativa. Madrid: Dykinson, 2015, p. 9. ${ }^{16}$ ASÍS, Rafael de. et al. (Coords.). Sobre la Accesibilidad Universal en el Derecho. Cuadernos “Bartolomé de las Casas", No. 42. Madrid: Dykinson, 2007, p. 17. 
humanos, visando a proporcionar dignidade a todas as pessoas, sem exceção. ${ }^{17}$ Palacios e Bariffi destacam que o modelo social possui os mesmos valores que fundamentam os direitos humanos, como a dignidade, a autonomia, a igualdade e a solidariedade. A causa da deficiência não é mais religiosa, nem médico-científica, mas preponderantemente social; ela é causada por limitações sociais (e não individuais), de um ambiente que não presta serviços apropriados, nem dá conta das necessidades das pessoas. É uma construção e um modo de opressão da sociedade, que deriva da não consideração dessas pessoas. $\mathrm{O}$ modelo propõe a reabilitação ou normalização da sociedade, que deve ser projetada para atender às necessidades de todas as pessoas sem distinção. ${ }^{18}$

Como ressalta Rodrigues, o modelo em questão "aponta o caminho da transformação cultural e paradigmática da sociedade, transformando espaços, práticas sociais e promovendo experiências coletivas em direção à sociedade inclusiva e, portanto, com igualdade de condições." ${ }^{19}$ Assim, ao se pensar em qualquer empreendimento ou projeto, todos os seus possíveis usuários/destinatários devem ser levados em consideração (os quais podem ter, ou não, deficiência), sob a ótica do desenho universal.

Feitos esses esclarecimentos preliminares sobre os significados de segregação (ou exclusão), integração e inclusão, a partir da interpretação de prescrições de documentos-chave internacionais, pretendemos extrapolar o âmbito de análise dogmático-jurídica. Tendo isso em vista, examinaremos os discursos de deficiência de Michel Foucault e de Martha Nussbaum. Michel Foucault, através da crítica histórica, lança seu olhar sobre o modelo médico de segregação ou exclusão, enquanto Martha Nussbaum, ao criticar a teoria moral de Kant e a de justiça procedimental de Rawls, propõe um modelo social mais inclusivo para as pessoas com deficiência. O modelo médico de integração não será, portanto, discursivamente abordado aqui.

17 VIVARTA, Veet (coord.) Mídia e Deficiência. Brasília: Andi; Fundação Banco do Brasil, 2003, p. 38.

18 PALACIOS, Agustina; BARIFFI, Francisco. La discapacidad como una cuestión de derechos humanos: una aproximación a la Convención Internacional sobre los Derechos de las Personas con Discapacidad. Madrid: Cinca, 2007, p. 19/21-22. ${ }^{19}$ RODRIGUES, Naira. Artigo 5: igualdade e não-discriminação. In: Joelson Dias, et al. (Orgs.). Novos Comentários à Convenção sobre os Direitos das Pessoas com Deficiência. $3^{a}$ ed. Brasília, DF: Secretaria de Direitos Humanos da Presidência da República, 2014, p. 53. 


\section{Michel FoucAult}

O discurso de Michel Foucault sobre a deficiência se centra no tempo histórico-político da Idade Média ao início do século XX e coloca em evidência os significados de segregação (ou exclusão) das pessoas com deficiência ao longo desse período.

Foucault nos ensina, em suas aulas de 1974-75 sobre Os Anormais, que o discurso das instâncias de poder político, médico e judicial da anormalidade nesse período histórico foi caracterizado como "grotesco" ou "ubuesco", isto é, tais instâncias de poder fundavam seus discursos com base no pressuposto da desqualificação do sujeito sobre o qual se fala. ${ }^{20}$ Para Foucault, esse posicionamento do poder não é um incidente, falha ou mera coincidência histórica, mas, sim, intencionalmente produzido pelas instâncias de controle de poder político, médico e judicial. O sujeito, considerado "desqualificado" e, portanto, "anormal" 21 , era, para as instituições detentoras de poder, um transgressor da lei. Seu desejo de violá-la é "correlativo de uma falha, de uma ruptura, de uma fraqueza, de uma incapacidade do sujeito" 22 .

Entre os monstros, os anormais incapazes, do ponto de vista das instâncias de poder, lista Foucault o "leproso", o "pestilento", "o masturbador", o "homossexual", o "déspota", o "incestuoso", o "obcecado", o "perverso", o "imbecil", o "coxo e outras aberrações". ${ }^{23}$

Essas personagens se inserem no discurso de Foucault sobre a anomalia e são sistematizadas pelo autor numa tipologia específica de anormalidade centrada em três figuras centrais:

1) O monstro humano;

2) O indivíduo a ser corrigido; e

${ }^{20}$ FOUCAULT, Michel. Os Anormais: curso no Collège de France (1974-1975). 2 2․ ed. Trad. Eduardo Brandão. São Paulo, SP: WMF Martins Fontes, 2010, p. 11.

${ }^{21}$ FOUCAULT, Michel. Os Anormais: curso no Collège de France (1974-1975). 2a. ed. Trad. Eduardo Brandão. São Paulo, SP: WMF Martins Fontes, 2010, p. 80 e ss.

${ }^{22}$ FOUCAULT, Michel. Os Anormais: curso no Collège de France (1974-1975). $2^{\mathrm{a}}$. ed. Trad. Eduardo Brandão. São Paulo, SP: WMF Martins Fontes, 2010, p. 19.

${ }^{23}$ FOUCAULT, Michel. Os Anormais: curso no Collège de France (1974-1975). 2 $2^{\mathrm{a}}$. ed. Trad. Eduardo Brandão. São Paulo, SP: WMF Martins Fontes, 2010, p. 3738/50/62/80/86-87/126/267-268/275. 


\section{3) A criança masturbadora. ${ }^{24}$}

A primeira dessas figuras é o monstro humano e o seu contexto de referência é a lei. A noção de monstro é essencialmente uma noção jurídica, diz Foucault. Isso porque a sua constituição existencial e de forma viola as leis da sociedade e da natureza. O monstro suscita, como resposta da lei, "a violência, a vontade de supressão pura e simples", ou ainda a intervenção médica, seus cuidados, ou a piedade. Ele se coloca, assim, automaticamente fora da lei. ${ }^{25}$

A segunda figura é a do "indivíduo a ser corrigido". Seu contexto é mais limitado do que o do "monstro humano", transgressor das leis universais cosmológicas. Sua referência básica é a própria família, em suas interações com as instituições que a circundam, isto é, a escola, a rua, o bairro, a igreja, a polícia, etc. Mas sua ocorrência é mais frequente, regular, familiar, cotidiana que a do "monstro humano", que socialmente se evidencia como uma excepcionalidade. ${ }^{26}$

A terceira figura é a do "masturbador", mais precisamente a da "criança masturbadora". Diferentemente das figuras anteriores, que têm seu apogeu nos séculos XVII/XVIII, a "criança masturbadora" é uma personagem própria do século XIX. Diferentemente do "monstro humano", cujas referências são a sociedade e a natureza, e do "indivíduo a ser corrigido", que se revela na interação existente entre a família e o seu entorno, o espaço de referência da "criança masturbadora" é, como afirma Foucault, um espaço bem mais restrito, é a microcélula familiar, "é o quarto, a cama, o corpo; são os pais, os tomadores de conta imediatos, os irmãos e irmãs; é o médico." 27

Neste artigo, vamos nos centrar na primeira figura, a do "monstro humano". O "monstro", assim, é o transgressor dos limites naturais, das classificações, da lei como quadro, instituída por Deus e pelos homens. ${ }^{28}$ O significado de "monstro", nesse contexto, não é originariamente uma noção médica, mas jurídica. Foucault esclarece que, já no Direito Romano,

${ }^{24}$ FOUCAULT, Michel. Os Anormais: curso no Collège de France (1974-1975). 2ª ${ }^{\text {. ed. }}$ Trad. Eduardo Brandão. São Paulo, SP: WMF Martins Fontes, 2010, p. 47.

${ }^{25}$ FOUCAULT, Michel. Os Anormais: curso no Collège de France (1974-1975). 2a ${ }^{\mathrm{a}}$. ed.

Trad. Eduardo Brandão. São Paulo, SP: WMF Martins Fontes, 2010, p. 48.

${ }^{26}$ FOUCAULT, Michel. Os Anormais: curso no Collège de France (1974-1975). 2a․ ed.

Trad. Eduardo Brandão. São Paulo, SP: WMF Martins Fontes, 2010, p. 49.

${ }^{27}$ FOUCAULT, Michel. Os Anormais: curso no Collège de France (1974-1975). $2^{\mathrm{a}}$. ed.

Trad. Eduardo Brandão. São Paulo, SP: WMF Martins Fontes, 2010, p. 50.

${ }^{28}$ FOUCAULT, Michel. Os Anormais: curso no Collège de France (1974-1975). 2a․ ed.

Trad. Eduardo Brandão. São Paulo, SP: WMF Martins Fontes, 2010, p. 54.

2 JOURNAL OF INSTITUTIONAL STUDIES 2 (2016) 
distinguiam-se duas categorias: a categoria da deformidade, da enfermidade, do defeito (o disforme, o enfermo, o defeituoso) e o monstro propriamente dito. Da Idade Média ao século XVIII, esse "monstro", do qual se ocupa Foucault, é, em verdade, para as instituições de poder, $o$ misto;

1) O misto de dois reinos: o reino animal e o reino humano, como o homem com cabeça de boi ou pés de ave;

2) O misto de dois indivíduos: o que tem duas cabeças e um corpo, o que tem dois corpos e uma cabeça; o que tem dois sexos: quem é ao mesmo tempo homem e mulher, assim como é;

3) O misto da vida e da morte: o feto que vem à luz com uma determinada morfologia de tal forma que não tem condições de sobrevivência; ou

4) O misto de formas: os indivíduos que não têm perna e se arrastam pelo chão como uma cobra.

Só há monstruosidade onde a desordem da lei natural vem tocar o direito, seja o direito civil, o canônico ou o religioso. É no ponto de encontro entre a lei terrena e a lei divina que vai se diferenciar a "enfermidade" da "monstruosidade". A enfermidade não é uma monstruosidade. Ela é normalizada, regulada pelo direito. A monstruosidade, ao contrário, é uma irregularidade natural que questiona o direito e com a qual ele não consegue funcionar. Como o direito é obrigado a se interrogar em face da monstruosidade os seus fundamentos e as suas práticas, ele acaba por se calar sobre ela ou renunciar a ela ou a apelar para um outro sistema de referência, como sistema médico, e ao direito canônico ou religioso. ${ }^{29}$ Foucault dá o exemplo do direito das sucessões:

Um homem morre, sua mulher está grávida; ele faz um testamento em que diz: "Se o filho que minha mulher espera vier a termo, herdará todos os meus bens. Se, ao contrário, a criança não nascer ou nascer morta, se for natimorto, então os bens passarão para a minha família." Se nasce um monstro, para quem irão os bens? Deve-se considerar que o filho nasceu ou que não nasceu? A partir do momento em que nasce essa espécie de vida e de morte que é a criança monstruosa, coloca-se para o direito um problema insolúvel. Quando nasce um monstro com dois corpos, ou com duas cabeças, deve receber um ou

${ }^{29}$ FOUCAULT, Michel. Os Anormais: curso no Collège de France (1974-1975). $2^{\mathrm{a}}$. ed. Trad. Eduardo Brandão. São Paulo, SP: WMF Martins Fontes, 2010, p. 54. 
dos batismos? Deve-se considerar que o casal teve um filho ou dois? ${ }^{30}$

Foucault levanta tais questionamentos com base em literatura do século XVIII, especificamente do autor F.E. Cangiamila, intitulada Resumo da embriologia sagrada ou tratado dos deveres dos padres, dos médicos e outros, sobre a saúde eterna das crianças que estão no ventre da sua mãe de $1762 .{ }^{31}$

No campo do direito penal, levanta o questionamento de dois irmãos siameses, um dos quais cometeu um crime. O problema era decidir se era para executar um ou os dois, pois se executasse um, o outro morreria. Se se deixasse o inocente viver, o outro, que cometeu o crime, também continuaria a viver. Nesse segundo caso, toma como referência o autor $\mathrm{H}$. Sauval da obra História e pesquisas das antiguidades da cidade de Paris de $1724 .{ }^{32}$

Tanto no primeiro quanto no segundo caso, Foucault não se utiliza de peças processuais.

Em nossa interpretação de Foucault, os anormais, os "monstros humanos" se referem aos sujeitos com múltiplas formas deficiência física, mental ou intelectual. Em seu discurso, tais indivíduos, historicamente considerados "monstros humanos", foram segregados ou excluídos do sistema jurídico, que os colocou, em todo o evoluir histórico, até o século XIX, onde termina a sua análise, à margem do quadro de normalidade jurídica. O sistema jurídico, por não encontrar em si fundamentos justificados da deficiência, ignorou ou apelou a um outro sistema de referência, eclesiástico ou médico, para justificar a aplicação da lei. Nesse sentido, as múltiplas formas de deficiência não tinham como serem normalizadas, pois eram, pelo sistema jurídico, consideradas infratoras, infratoras das classificações formais e existenciais do que foi historicamente considerado como "normal". Nascer e existir como deficiente, de acordo com a nossa análise de Foucault, era, em sua origem, uma subversão, pois contra natural, contra biológico, contra cosmológico, contra religioso, contra jurídico, contra legem. Assim é que os sistemas jurídico e médico, as duas instâncias de poder principais trabalhadas por Foucault em Os Anormais, desqualificaram, descapacitaram e

${ }^{30}$ FOUCAULT, Michel. Os Anormais: curso no Collège de France (1974-1975). 2a․ ed. Trad. Eduardo Brandão. São Paulo, SP: WMF Martins Fontes, 2010, p. 55.

${ }^{31}$ CANGIAMILA, François-Emmanuel. Abrege de l'embryologie sacree au Traite des devoirs des prêtres, des médecins, des chirurgiens et des sages-femmes envers les enfans qui sont dans le sein de leurs mères. Paris: Nyon, 1762.

32 SAUVAL, Henri. Histoire et recherches des antiquités de la ville de Paris. Paris: Chés C. Moétte/J. Chardon, 1724.

2 JOURNAL OF INSTITUTIONAL STUDIES 2 (2016) 
desumanizaram o ser nascido com alguma forma de deficiência. ${ }^{33}$ Desumanizando-o, tais instâncias de poder acabaram por desconhecê-lo, excluí-lo ou segregá-lo. Essa é a interpretação mais evidente

A segunda interpretação, não tão evidente assim, é que a anormalidade obedece a uma dialética de anormalidade-normalidade. Desqualifica-se o sujeito com deficiência para normalizá-lo. A desqualificação promovida pelo Direito, que é abalado pela anormalidade e reage a ela, "calando-se" sobre a deficiência, "renunciando" a ela ou "apelando" a outros sistemas para justificar a própria desqualificação, não implica desconhecê-la. Na desqualificação, já está ínsito o próprio reconhecimento e não o desconhecimento. A tentativa mesma de normalizar a deficiência, por meio da sua desqualificação, é também uma forma de reconhecimento do anormal. A consequência de segregação (ou exclusão) decorre, nesta segunda interpretação, do reconhecimento pelo sistema jurídico da existência de um ser, como diz Foucault, misto, não-humano.

\section{MARTHA NUSSBAUM}

Martha Nussbaum discute, em sua obra Fronteiras da Justiça: Deficiência, Nacionalidade, Pertencimento à Espécie, ${ }^{34}$ a questão da inclusão no contrato social clássico, de base racionalista e kantiana, assim como o contrato social contemporâneo, de base rawlsiana. Questiona tanto no primeiro quanto no segundo tipo de contrato a exclusão de grupos minoritários, como o das pessoas com deficiência. Para tanto, ela se volta à abordagem das capacidades humanas, no sentido de habilidades, funcionamentos humanos. Nussbaum lista dez capacidades (e direitos correspondentes), que podem ser consideradas como requisitos fundamentais de uma vida com dignidade. ${ }^{35}$ São elas: vida; saúde

${ }^{33}$ FOUCAULT, Michel. Os Anormais: curso no Collège de France (1974-1975). 2ª ${ }^{\text {. ed. }}$ Trad. Eduardo Brandão. São Paulo, SP: WMF Martins Fontes, 2010.

${ }^{34}$ Cf. NUSSBAUM, Martha. Frontiers of Justice: Disability, Nationality, Species

Membership. Edição Kindle. Cambridge, MA: Belknap Press of Harvard University Press, 2007; e NUSSBAUM, Martha. Fronteiras da Justiça: Deficiência, Nacionalidade, Pertencimento à Espécie Trad. Susana de Castro. São Paulo, SP: WMF Martins Fontes, 2013.

35 "The basic idea is that with regard to each of these, we can argue, by imagining a life without the capability in question, that such a life is not a life worthy of human dignity. [...] Indeed, the capabilities approach is, in my view, one species of a human 
corporal; integridade física; sentidos, imaginação e pensamento; emoções; razões práticas (proteção para a liberdade de consciência e deveres religiosos); afiliação; capacidade de viver e se preocupar com outras espécies (referindo-se a animais, plantas e mundo da natureza) ${ }^{36}$; brincar e ter controle sobre o próprio ambiente ${ }^{37}$. Vale destacar que Nussbaum elenca não só a capacidade de viver e de se preocupar com outras espécies, mas também o que denomina de afiliação, que significa ser capaz de viver com e voltado para outros e ter as bases sociais de autorrespeito e não humilhação e, nessa medida, ser capaz de ser tratado como um ser digno. A dignidade humana justifica, portanto, a inclusão social das pessoas com deficiência, manifestada sob a forma dessa lista propositiva de capacidades.

A inclusão social, compreendida a partir da dignidade humana e das capacidades das pessoas com deficiência, não se baseia, para Nussbaum, em um discurso do tipo moral, racionalista e iluminado à la Kant. Em verdade, Nussbaum rejeita a teoria moral kantiana e a ela tece crítica específica. De acordo com Kant, é o atributo da razão que determina a capacidade humana de julgamento moral. É a razão também que, ao nos caracterizar como humanos, ao mesmo tempo nos separa da nossa própria animalidade e dos animais não-humanos.

Segundo Nussbaum, Kant divide o mundo em dois reinos: o da necessidade natural e o da liberdade racional e moral. Ele vê todo animal não-humano e o lado animal da vida humana como pertencentes ao campo determinístico da natureza. Por isso, a dignidade humana e a nossa capacidade moral, fontes da dignidade, estão radicalmente separadas nessa perspectiva do mundo natural. Assim, segundo a interpretação de Nussbaum sobre Kant, se existimos meramente no

rights approach, and human rights have often been linked in a similar way to the idea of human dignity." NUSSBAUM, Martha. Frontiers of Justice: Disability, Nationality, Species Membership. Edição Kindle. Cambridge, MA: Belknap Press of Harvard University Press, 2007, chapter 1, location 929-5408.

36 "Other Species. Being able to live with concern for and in relation to animals, plants, and the word of nature." NUSSBAUM, Martha. Frontiers of Justice: Disability, Nationality, Species Membership. Edição Kindle. Cambridge, MA: Belknap Press of Harvard University Press, 2007, chapter 1, location 922-5408.

37 "But in some form all are held to be part of a minimum account of social justice: a society that does not guarantee these to all its citizens, at some appropriate threshold level, falls short of being a fully just society, whatever its level of opulence." NUSSBAUM, Martha. Frontiers of Justice: Disability, Nationality, Species Membership. Edição Kindle. Cambridge, MA: Belknap Press of Harvard University Press, 2007, chapter 1, location 901-5408. 
campo da natureza, não somos fins em nós mesmos e não temos dignidade. As coisas, complementa ela, possuem, neste campo, um preço, mas não dignidade. Por isso que a animalidade, em Kant, não é um fim em si mesmo. Considera Nussbaum que a separação entre "humanidade" e "animalidade" em Kant é, por tudo isso, extremamente problemática. A fim de corroborar essa conclusão argumentativa, ela enumera três fatores:

1) Em realidade, a dignidade humana é uma dignidade de um tipo específico de animal;

2) A separação kantiana em dois reinos despreza aspectos de nossas vidas que possuem valor e distorce nossas relações com os animais;

3) Essa separação sugere, ainda, que a nossa pessoalidade é autossuficiente e puramente ativa e, não, necessitada e também passiva. Ignora, assim, o "fato de que a doença, o envelhecimento e um acidente podem impedir da mesma forma tanto funções morais e racionais quanto as demais funções animais." 38

A dignidade kantiana ignora esse ciclo natural da vida. Ignora, por conseguinte, os períodos, que nos podem suceder, de extrema dependência, semelhante àquela que sucede durante toda a vida com as pessoas que já nascem com uma deficiência mental. Em Kant, segundo Nussbaum, a nossa racionalidade é independente de nossa animalidade vulnerável. Isso, na visão da autora, é um equívoco central da teoria moral kantiana.

$\mathrm{Na}$ abordagem de Nussbaum sobre as capacidades humanas (que corresponderiam à lista propositiva de direitos humanos a ser introduzida nas Constituições de países democráticos), a racionalidade e a animalidade são concepções unificadas. Para justificar a sua tese, a autora recorre à concepção aristotélica do ser humano como animal político e a racionalidade como simplesmente um aspecto dessa animalidade. O enfoque das capacidades de Nussbaum propõe, portanto, que existam muitos tipos diferentes de dignidade animal no mundo; entre eles, o tipo especificamente humano.

A dignidade humana, em sua visão, não é uma racionalidade idealizada, contraposta à animalidade. Consiste em uma variedade de

${ }^{38}$ NUSSBAUM, Martha. Fronteiras da Justiça: Deficiência, Nacionalidade,

Pertencimento à Espécie Trad. Susana de Castro. São Paulo, SP: WMF Martins Fontes, 2013, p. 165.

2 JOURNAL OF INSTITUTIONAL STUDIES 2 (2016) 
formas de raciocínio prático, isto é, é um dos modos de funcionalidade dos animais, somada à sociabilidade e à necessidade corporal (incluindo a necessidade por cuidado, que é uma característica da nossa racionalidade e da nossa sociabilidade).

As capacidades humanas são maneiras efetivas, diz Nussbaum, de se ter uma vida com dignidade. A dignidade, assim, não é definida antes e independentemente das capacidades, mas, sim, de um modo imbricado com elas e com suas definições.

Em nossa interpretação, o discurso teórico de Nussbaum não rejeita o contratualismo, apenas alarga o número de seus participantes e confere a ele um caráter menos idealizado e mais concretamente prático, político e social. O contrato, em sua visão, que perfaz e dita os princípios fundamentais, como o da dignidade humana, e os direitos desse contrato, evidencia-se através de sua lista de capacidades humanas. Esse contrato de Nussbaum pretende ser mais inclusivo do que o contrato originário, no sentido de abranger outros sujeitos que não tiveram qualquer participação no contrato social clássico do tipo iluminista kantiano ou contemporâneo rawlsiano. Em sua visão, as pessoas com deficiência devem também sobre ele consentir. Mas que pessoas com deficiência seriam essas? São aquelas que estão aptas a aceder a "um nível mínimo para cada uma das capacidades, isto é, um mínimo abaixo do qual não há uma vida decentemente digna" ${ }^{39}$. Nussbaum ressalta que "uma vida sem nenhuma possiblidade de exercer alguma delas [dessas capacidades], em qualquer nível não pode ser considerada uma vida plenamente humana." ${ }^{40}$ Assim, ela exclui as pessoas com deficiências extremas, como as pessoas em estado vegetativo permanente e as crianças com anencefalia Nesses casos, "não apenas a mera vida, mas a boa vida tornase impossível". ${ }^{41} \mathrm{~A}$ inclusão, portanto, de acordo com o discurso da autora, abrange as pessoas com múltiplas formas de deficiências graves, mas não as extremas ou profundas que impeçam a pessoa de estabelecer qualquer vínculo com o meio familiar e social.

${ }^{39}$ NUSSBAUM, Martha. Fronteiras da Justiça: Deficiência, Nacionalidade,

Pertencimento à Espécie Trad. Susana de Castro. São Paulo, SP: WMF Martins Fontes, 2013, p. 220.

${ }^{40}$ NUSSBAUM, Martha. Fronteiras da Justiça: Deficiência, Nacionalidade,

Pertencimento à Espécie Trad. Susana de Castro. São Paulo, SP: WMF Martins Fontes, 2013, p. 222.

${ }^{41}$ NUSSBAUM, Martha. Fronteiras da Justiça: Deficiência, Nacionalidade,

Pertencimento à Espécie Trad. Susana de Castro. São Paulo, SP: WMF Martins Fontes, 2013, p. 222.

2 JOURNAL OF INSTITUTIONAL STUDIES 2 (2016) 


\section{CONCLUSÃO}

Em uma comparação dos dois discursos, podemos concluir que o discurso de Foucault sobre a anormalidade, embora critique como o "monstro humano" foi percebido e tratado até o início do século XX pelas instâncias de poder médico e jurídico, e o de Martha Nussbaum pretenda alargar o número de partícipes do contrato social e incluir nele as pessoas com deficiência a partir da dignidade humana, fato é que tanto no discurso crítico de Foucault quanto no discurso liberal-socialdemocrático de Nussbaum, a deficiência mental profunda é excluída. Ambos não lançam suficientemente luz, por exemplo, sobre as acefalias e microcefalias. No caso de Foucault, o que ele denomina de misto da vida e da morte deveria ter sido examinado com mais profundidade, com base não só em uma literatura secundária mais ampla, mas também em processos judiciais. Falta ainda certa sofisticação em Nussbaum ao trabalhar a dignidade humana como fundamento da inclusão das deficiências mentais graves, e não inclusão das deficiências mentais profundas. Nesse caso específico, mais em Nussbaum do que em Foucault, a acefalia é excluída do discurso contemporâneo de inclusão de todas as formas de deficiência. $\mathrm{O}$ mesmo se passa com o paciente em coma vegetativo persistente também excluído por Nussbaum. Tendo tudo isso em vista, faz-se necessária, portanto, uma interpretação mais atualizada do discurso da anormalidade de Foucault sobre as deficiências mentais profundas. Já a respeito do discurso de Nussbaum, consideramos também indispensável uma análise mais específica de o porquê as deficiências mentais profundas, como as logo acima exemplificadas, serem excluídas de seu discurso.

\section{REFERÊNCIAS}

ASÍS, Rafael de. et al. (Coords.). Sobre la Accesibilidad Universal en el Derecho. Cuadernos "Bartolomé de las Casas", No. 42. Madrid:

Dykinson, 2007. 
BARBOSA-FOHRMANN, Ana Paula; KIEFER, Sandra Filomena Wagner. Modelo Social de Abordagem dos direitos humanos das pessoas com deficiência. In: Joyceane Bezerra Menezes (Org.). Direito das pessoas com deficiência psíquica e intelectual nas relações privadas: Convenção sobre os direitos da pessoa com deficiência e Lei Brasileira de Inclusão. Rio de Janeiro, RJ: Editora Processo, 2016.

CANGIAMILA, François-Emmanuel. Abrege de l'embryologie sacree au Traite des devoirs des prêtres, des médecins, des chirurgiens et des sages-femmes envers les enfans qui sont dans le sein de leurs mères. Paris: Nyon, 1762.

DEL ÁGUILA, Luis Miguel. La Autonomía de las Personas con Discapacidad como Principio Rector. In: Elizabeth Salmón y Renato Bregaglio (Coords.). Nueve Conceptos Claves para Entender la Convención sobre los Derechos de las Personas con Discapacidad. Lima: Pontificia Universidad Católica del Perú, Instituto de Democracia y Derechos Humanos (IDDHPUCP), 2015.

ESTEBAN, Amparo Cano, et. al. (Coords.) Discapacidad y Políticas Públicas: la experiencia real de la juventud con discapacidad en España. Madrid: Catarata, 2015.

FERREIRA, Vandir da Silva; OLIVEIRA, Lilia Novais de. Convenção sobre os Direitos das Pessoas com Deficiência. Associação Nacional dos Membros do Ministério Público de Defesa dos Direitos dos Idosos e Pessoas com Deficiência (AMPID), 2007. Disponível em:

$<$ http://www.ampid.org.br/ampid/Artigos/Convencao Vandir Lilia.php >. Acesso em: 23 de outubro de 2015.

FONSECA, Ricardo Tadeu Marques da. A ONU e seu Conceito Revolucionário de Pessoa com Deficiência. Associação Nacional dos Membros do Ministério Público de Defesa dos Direitos dos Idosos e Pessoas com Deficiência (AMPID), 2008. Disponível em: 
<http://www.ampid.org.br/ampid/Artigos/Onu Ricardo Fonseca.php $>$. Acesso em: 19 de outubro de 2015.

FOUCAULT, Michel. Os Anormais: curso no Collège de France (19741975). $2^{a}$. ed. Trad. Eduardo Brandão. São Paulo, SP: WMF Martins Fontes, 2010.

MARTÍNEZ, María Olga Sánchez; CAYÓN, José Ignacio Solar. La Convención Internacional sobre los Derechos de las Personas con Discapacidad y su Impacto en la Legislación Autonómica de Cantabria: propuestas de reforma legislativa. Madrid: Dykinson, 2015.

NUSSBAUM, Martha. Fronteiras da Justiça: Deficiência, Nacionalidade, Pertencimento à Espécie Trad. Susana de Castro. São Paulo, SP: WMF Martins Fontes, 2013.

. Frontiers of Justice: Disability, Nationality, Species

Membership. Edição Kindle. Cambridge, MA: Belknap Press of Harvard University Press, 2007.

PALACIOS, Agustina; BARIFFI, Francisco. La discapacidad como una cuestión de derechos humanos: una aproximación a la Convención Internacional sobre los Derechos de las Personas con Discapacidad. Madrid: Cinca, 2007.

RODRIGUES, Naira. Artigo 5: igualdade e não-discriminação. In: Joelson Dias, et al. (Orgs.). Novos Comentários à Convenção sobre os Direitos das Pessoas com Deficiência. $3^{\underline{a}}$ ed. Brasília, DF: Secretaria de Direitos Humanos da Presidência da República, 2014.

RODRÍGUEZ, José Antonio Cagigas. Prefacio. In: MARTÍNEZ, María Olga Sánchez; CAYÓN, José Ignacio Solar. La Convención Internacional sobre los Derechos de las Personas con Discapacidad y 
su Impacto en la Legislación Autonómica de Cantabria: propuestas de reforma legislativa. Madrid: Dykinson, 2015

SALMÓN, Elizabeth. El Comité de los Derechos de las Personas con Discapacidad o la Institucionalidad del Derecho Internacional de los Derechos Humanos al Servicio de las Personas con Discapacidad. In: Elizabeth Salmón y Renato Bregaglio (Coords.). Nueve Conceptos Claves para Entender la Convención sobre los Derechos de las Personas con Discapacidad. Lima: Pontificia Universidad Católica del Perú, Instituto de Democracia y Derechos Humanos (IDDHPUCP), 2015.

SAUVAL, Henri. Histoire et recherches des antiquités de la ville de Paris. Paris: Chés C. Moétte/J. Chardon, 1724.

VIVARTA, Veet (Coord.) Mídia e Deficiência. Brasília, DF: Andi; Fundação Banco do Brasil, 2003.

Os Modelos Médico e Social de Deficiência a partir dos Significados de Segregação e Inclusão nos Discursos de Michel Foucault e de Martha Nussbaum The Medical and Social Models of Disability from the Meanings of Segregation and Inclusion in Michel Foucault's and Martha Nussbaum's Discourses Submetido em: 2016-12-04 Aceito em: 2017-01-30 